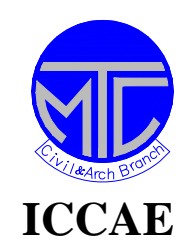

Military Technical College

Kobry Elkobbah,

Cairo, Egypt

$7^{\text {th }}$ International Conference

On Civil \& Architecture

Engineering

\title{
Finite Element Analysis of Curved Thin-Walled Panels
}

\section{Authors:}

Nashwa M. Yossef, Tanta University, Tanta, Egypt, nashwa.yossef@gmail.com, Tel. +224107954

M. El-Aghoury, Ain Shams University, Cairo,Egypt, aghoury_tc@yahoo.com

M. A. Dabaon, Tanta University, Tanta,Egypt,m_dabaon@yahoo.com

M. H. El-Boghdadi, Tanta University, Tanta,Egypt, mhboghdadi@yahoo.com

M. Hassanen, Univ. of Strathclyde, Glasgow, United Kingdom, mahmoud.hassanen@gmail.com

\begin{abstract}
Two previous published papers by the writers describing the nonlinear behavior of curved Igirder web panels subjected to pure bending, were presented including experimental and theoretical analysis. The web slenderness limitation was also presented. A finite element analysis was needed to validate the applicability of the web slenderness limitation. This paper presents geometrical nonlinear finite element analysis for curved panels. To simulate the behavior of curved thin-walled panel subjected to pure bending, three dimensional model is presented. The effect of flange slenderness on the web buckling was also investigated. The flange slenderness limitation of the straight panel presented in Euro Code 3 is used for calculating the flange slenderness limitation for curved thin-walled panel.
\end{abstract}

\section{INTRODUCTION}

Despite the numerous advantages and the increasing demand, the curved girder system has not been employed much in practice primarily due to the lack of information on its complex structural behavior [1].

For I-shaped structure, efficient flexure design requires that the flange plate carries most of the primary moment and the web designed as slender as possible. Therefore, the existing web slenderness limitation in codes is based on buckling consideration. In case of curved girder, the presence of curvature complicates the behavior and design consideration. Whereas curvature causes the membrane stresses in the web to be nonlinear and, most important, to increase the outof-plane displacement, which, directly put more restriction on the slenderness of the web. 
The current web-slenderness limitation for curved I-girder stated in the Guide Specifications for Horizontally Curved Highway Bridge (AASHTO) are based largely on the analytical study conducted by Culver et al [2]. In this study, the curved web panel was studied using simplified finite strip model. Numerical results were generated by the reduction of the effective moment to produce initial yield in the flange. The deflection and web bending stresses for girders with curvature corresponding to the initial imperfection limit of $d / 120$ ( $d$ is the depth of the panel) were used to develop a design criteria for curved girders. Numerical results based on this limit were generated and the web slenderness requirement $\left(d / t_{w}\right.$ is the slenderness of the web and $t_{w}$ is its thickness) was derived. This web slenderness limitation derived by Culver et al [2] was based on a simple curve fitting of numerical result data. Also, the derived equation was based on panel aspect ratios $(\mathrm{a} / \mathrm{d})$ of $1.5\left(\mathrm{a}\right.$ is spacing between transverse stiffener $\left.=2 \mathrm{a}_{1}\right)$, and for $(\mathrm{a} / \mathrm{d})$ less than 1.5 the presented equation becomes conservative.

Nakai and Yoo [3] conducted analytical research on the elastic behavior of curved web plates subjected to bending using the finite element analysis method. The web slenderness limitation was based on curve fitting of finite element analysis results for a model representing un-stiffened longitudinal curved girder.

An in-depth account of the curvature effects on web panel under bending was presented by Davidson et al [4]. A simplified finite element model was used to evaluate the curvature effect on the behaviour of curved thin walled panel. The out-of-plane displacements of the web were then approximated using a "lateral pressure analogy". The lateral pressure analogy determined the maximum displacement and bending stress in the panel. Davidson et al [4] showed that the presented model was inaccurate because it was based upon small displacement theory and linear distribution of stresses along the web depth. For this reason geometric nonlinear analysis was conducted by Davidson et al [5] to quantify the amount of amplification using the finite element model.

A wide study was presented by Yossef N. M. et al [6] to provide a consistent formulation of the set of equations governing stability and nonlinear behavior of thin-walled curved panel for Igirder subjected to bending about the major axis. The proposed approach was based on strain compatibility equation and the minimum total potential energy. Solutions for these equations, including the out-of-plane deformation, were obtained numerically. Out-of-plane displacements were compared with the results of experimental tests of four medium size plate girders, by Dabaon et al [7], encouraging agreement was recorded. Limiting the out-of-plane displacement estimated by the proposed procedure, results in a web slenderness limit that take into account the panel curvature and depended on the panel dimension as shown in equation (1).

$\left(\frac{\mathrm{d}}{\mathrm{t}}\right)^{2}\left[\chi+\kappa \frac{\mathrm{N}_{\mathrm{o}}}{\mathrm{E}}\right]-\left(\frac{\mathrm{d} .}{\mathrm{t}}\right)^{3}\left[\frac{4 \beta \alpha^{4} \mathrm{~N}_{\mathrm{o}}(\pi-2)}{\pi^{3} \mathrm{E}}\right]+2.93 \xi\left(\alpha^{2} \pi^{2}+\left(\frac{\pi}{2}\right)^{2}\right)^{2}=0$

Where

$$
\begin{aligned}
& \chi=\frac{\xi^{3} \pi^{4}}{2}\left[\frac{3}{16}\left(-2+\frac{\beta^{2}}{\pi^{2}}\right)^{2}+\alpha^{4}\left(2+\frac{\beta^{2}}{\pi^{2}}\right)^{2}\right]+\frac{\xi \pi^{4}\left[(2 \alpha)^{4}+1+2 \alpha^{2}\right]\left(\frac{8 \beta \alpha^{3}}{\pi^{2}}\right)^{2}}{2\left(1+4 \alpha^{2}\right)^{4}} \\
& \kappa=\frac{\left[-16 \alpha^{2}+1.2\right]}{\left(1+4 \alpha^{2}\right)^{2}} \frac{16 \beta \alpha^{5}}{\pi^{2}}-\xi \pi^{2} \alpha^{2} \quad \text { and } \quad \alpha=\mathrm{a} / \mathrm{d}=1 \quad \beta=\mathrm{a} / \mathrm{R} \quad \xi=\mathrm{d} / w_{\max }
\end{aligned}
$$


$\mathrm{R}$ is the Radius of curvature, $w$ is the out-of-plane displacement and $\mathrm{N}_{\mathrm{o}}$ is the maximum stress at the web $\left(\mathrm{N}_{\mathrm{o}}=\mathrm{M} \cdot \mathrm{b} / \mathrm{I}\right)$

The purpose of this paper is to present the nonlinear finite element analysis for curved thinwalled panel subjected to pure bending. A three dimensional (3D) model for such panel is presented, the comparison between the presented model and the experimental tested panels [7] gives good agreement. The model is used in a parametric study for 10 groups of curved thin walled panels, the 10 groups consists of 78 panels. The effect of the flange slenderness on the web buckling is also studied for curved panel with the change of curvature, depth and aspect ratio. The flange slenderness limit for straight panel presented by Euro Code 3 is studied as a limit for curved panel which has the web slenderness limit presented in equation. (1).

\section{FINITE ELEMENT ANALYSIS}

Analysis of curved plate girders can be simplified by considering the critical panel subjected to a maximum bending moment or a maximum shear. For curved thin walled panel subjected to bending moment about the major axis, a wide experimental and theoretical study has been made. The first phase of the study involves the development of design equations for the nonlinear large deflection analysis of the curved thin-walled panel, equation (1), then the development of an accurate finite element model to simulate the nonlinear behavior of such panels is carried out. The finite element model is used to predict the stresses and deformations for the experimentally tested beams, 3D models for the tested panels are performed using ANSYS program version 11.

\section{DESCRIPTION OF THE MODEL}

Plastic quadrilateral shell elements, so called SHELL 181 in the library of ANSYS program, are used to model the panel web, flanges and stiffeners. The curved panel and also the stiffener are discriminated into a mesh consisting of quadratic shell elements, as shown in Fig. (1).

The material nonlinearity is modeled assuming the material yielding as defined by Von Mises yield function with isotropic material behavior. The stress-strain relationship was defined as; Bilinear Isotropic Hardening Plasticity (BISO). The nonlinear response in the loading path is solved by using the Newton iterative technique. Several tools in ANSYS program are used to improve the convergence performance in the analysis like the use of the automatic time stepping, solution control and bi-section.

A denser mesh is required to model the curved member to reflect its actual behavior. Finite element mesh with $16 \times 16$ element for the tested curved panel is used as based in Davidson and Yoo [4] \& [5], it was shown that this mesh resulted in adequate accuracy for flat and curved plate. Only one half of the girder is modeled using the advantage of symmetry about the mid span section.

The panel is supported such that, the translation in the $\mathrm{X}$ and $\mathrm{Z}$ directions are restrained along the bottom line of the end plate to simulate the movement of the panel itself, the movement of the panel with respect to the girder is ignored, and the radial translation in X direction of the top flange is restrained at the loaded section, as shown in Fig. (1). A triangular load, distributed along the height of the web and the width of the flange, is used to simulate the effect of bending moment. 

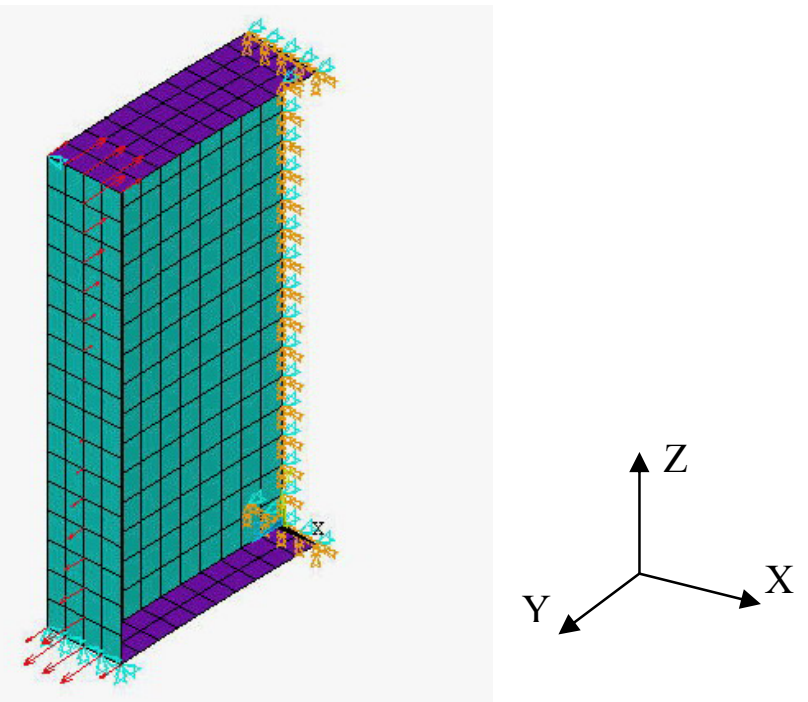

Fig. (1) A typical finite element mesh of tested panel

\section{FINITE ELEMENT AND EXPERIMENTAL RESULTS COMPARISON}

As evident in Fig. (2), the deformed shape for tested specimen B4 tested by Dabaon et al [7], is matching with this modeled by the finite element method.

As the determination of the ultimate moment capacities of the thin-walled girders is the most important objective of the finite element analysis, table (1) shows that the ultimate loads gained by the panels models are almost the same as those given experimentally [7].

Great concern is given to the strain distributions in the longitudinal direction of tested web panel. Fig (3) presents a comparison of the strain distribution for Dabaon [7] tested panel B3 and strain for panel model. 

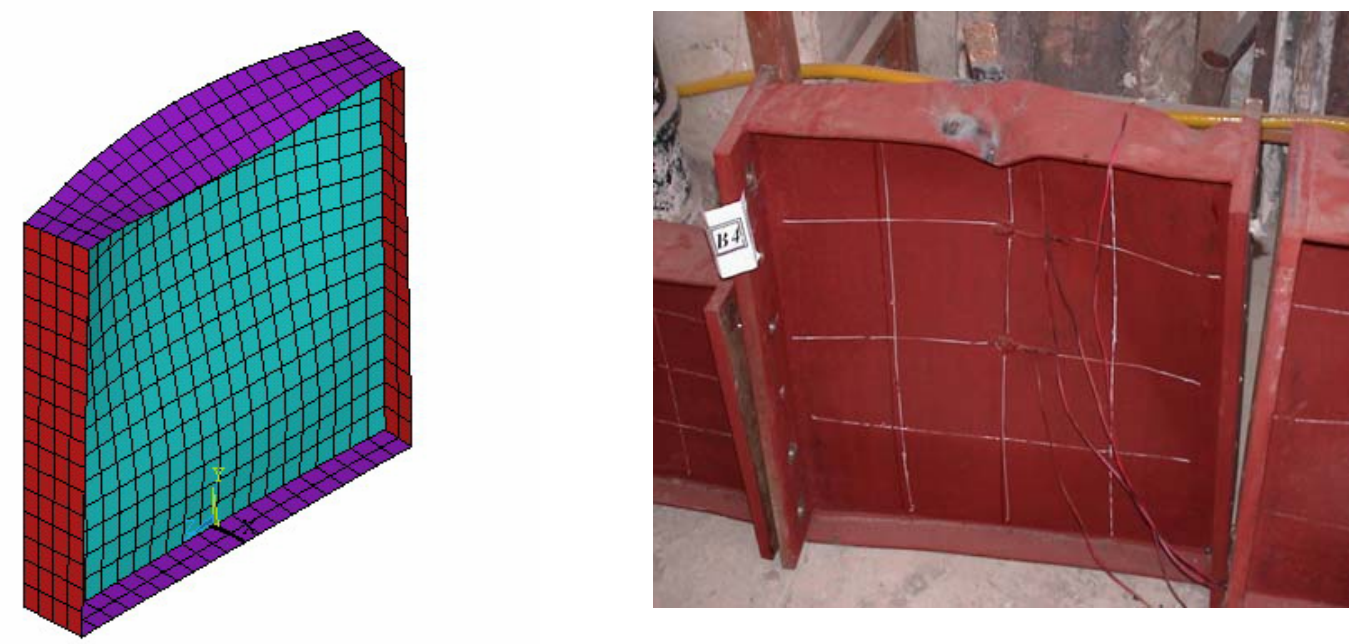

Fig. (2) Deformed shape for tested panel B4

Table (1) Comparison between the finite element model result and the experimental result [7]

\begin{tabular}{|c|c|c|c|c|c|c|c|}
\hline $\begin{array}{c}(1) \\
\text { Tested } \\
\text { panel }\end{array}$ & $\begin{array}{c}(2) \\
\text { Curvature } \\
\left(\mathbf{a}^{2} / 8 \mathrm{Rt}_{\mathrm{w}}\right)\end{array}$ & $\begin{array}{l}\text { (3) } \\
\text { a/d }\end{array}$ & $\begin{array}{c}(4) \\
d / t_{w}\end{array}$ & $\begin{array}{c}(5) \\
\mathbf{A}_{w} / \mathbf{A}_{f \mid}\end{array}$ & $\begin{array}{c}(6) \\
\text { Pu } \\
\text { (experimental) } \\
\text { (kN) [7] }\end{array}$ & $\begin{array}{c}\text { (7) } \\
\text { Pu } \\
(\text { F.E. } \\
\text { model) } \\
(\mathbf{k N})\end{array}$ & $\begin{array}{c}(8) \\
(\mathbf{6}) /(7)\end{array}$ \\
\hline B1 & 2.77 & 1 & 223.6 & 1.47 & 500 & 567 & 0.88 \\
\hline B2 & 3.41 & 1.5 & 144.1 & 2.13 & 230 & 254 & 0.91 \\
\hline B3 & 4.74 & 1.5 & 149.3 & 1.05 & 335 & 360 & 0.93 \\
\hline B4 & 3.77 & 1 & 225.1 & 2.98 & 450 & 424 & 1.06 \\
\hline
\end{tabular}

\section{PARAMETRIC STUDY VARIABLES}

The presented finite element model ensured a great confidence in dealing with behavior of curved thin-walled panel. This model is used in an extensive parametric study to validate the proposed equation (1) of web slenderness limitation $\mathrm{d} / \mathrm{t}_{\mathrm{w}}$. It was used also to find the effect of the flange slenderness on the ultimate moment capacity of curved thin-walled panels which have the limitation of the web slenderness.

Ten groups are used in the parametric study as shown in table (2). The first group (group 1) consists of 6 curved thin-walled panels with the radius of curvature $(R)$, flange width $\left(b_{f}\right)$ and web thickness $\left(t_{\mathrm{w}}\right)$. They were chosen to satisfy the recommended width of the vertical stiffener $(\mathrm{d} / 30+5 \mathrm{~cm})$ and the web slenderness limitation [6]. 
Table (2) parametric study variables

\begin{tabular}{|c|c|c|c|c|c|c|c|c|c|c|c|c|c|c|c|c|c|}
\hline \multirow{3}{*}{ No } & \multirow{3}{*}{ Panel name } & \multirow{3}{*}{$\begin{array}{c}\mathrm{d} \\
(\mathrm{cm})\end{array}$} & \multirow{3}{*}{$\begin{array}{c}\mathrm{a} / \mathrm{d} \\
(\mathrm{cm})\end{array}$} & \multirow{3}{*}{$\begin{array}{c}\mathrm{a} \\
(\mathrm{cm})\end{array}$} & \multirow{3}{*}{$\begin{array}{c}\mathrm{R} \\
(\mathrm{cm})\end{array}$} & \multirow{3}{*}{$\mathrm{a} / \mathrm{R}$} & \multirow{3}{*}{$\mathrm{d} / \mathrm{t}_{\mathrm{w}}$} & \multirow{3}{*}{$\begin{array}{c}\mathrm{t}_{\mathrm{w}} \\
(\mathrm{cm})\end{array}$} & \multirow{3}{*}{$b_{f}$} & \multicolumn{8}{|c|}{$\mathrm{t}_{\mathrm{f}}(\mathrm{cm})$} \\
\hline & & & & & & & & & & \multicolumn{8}{|c|}{$\mathrm{j}$} \\
\hline & & & & & & & & & & 1 & 2 & 3 & 4 & & 6 & 7 & 8 \\
\hline 1 & Bti-1-40-(1) & 100 & 1 & 100 & 4000 & 0.025 & $* *$ & $* * *$ & 18 & \multicolumn{8}{|c|}{2.25} \\
\hline 2 & $\mathrm{Bj}-2-20-(0.5)$ & 200 & 0.5 & 100 & 2000 & 0.05 & 103 & 2 & 24 & 4 & 3 & 2 & 1.5 & 1.2 & 1.0 & 0.8 & 0.6 \\
\hline 3 & Bj-2-40-(0.5) & 200 & 0.5 & 100 & 4000 & 0.025 & 130.3 & 1.6 & 24 & 4 & 3 & 2 & 1.5 & 1.2 & 1.0 & 0.8 & 0.6 \\
\hline 4 & Bj-2-60-(0.5) & 200 & 0.5 & 100 & 6000 & $\begin{array}{c}0.016 \\
6\end{array}$ & 150 & 1.4 & 24 & 4 & 3 & 2 & 1.5 & 1.2 & 1.0 & 0.8 & 0.6 \\
\hline 5 & Bj-2-80-(0.5) & 200 & 0.5 & 100 & 8000 & $\begin{array}{c}0.012 \\
5\end{array}$ & 165 & 1.3 & 24 & 4 & 3 & 2 & 1.5 & 1.2 & 1.0 & 0.8 & 0.6 \\
\hline 6 & Bj-1-40-(0.5) & 100 & 0.5 & 50 & 4000 & $\begin{array}{c}0.012 \\
5\end{array}$ & 94.12 & 1.2 & 18 & 3 & 2.25 & 1.5 & 1.12 & 0.9 & 0.75 & 0.6 & 0.45 \\
\hline 7 & $\begin{array}{c}\text { Bj-0.6-40- } \\
\quad(0.5)\end{array}$ & 60 & 0.5 & 30 & 4000 & $\begin{array}{c}0.007 \\
5\end{array}$ & 110.8 & 0.6 & 15 & 2.5 & 1.8 & 1.25 & 0.94 & 0.7 & 0.62 & 0.5 & 0.38 \\
\hline 8 & Bj-1-40-(1.5) & 100 & 1.5 & 150 & 4000 & $\begin{array}{c}0.037 \\
5\end{array}$ & 79 & 1.8 & 18 & 3 & 2.25 & 1.5 & 1.12 & 0.9 & 0.75 & 0.6 & 0.45 \\
\hline 9 & $\mathrm{Bj}-1-40-(1)$ & 100 & 1 & 100 & 4000 & 0.025 & 95 & 1.1 & 18 & 3 & 2.25 & 1.5 & 1.12 & 0.9 & 0.75 & 0.6 & 0.45 \\
\hline 10 & Bj-1-40-(0.66) & 100 & 0.66 & 66 & 4000 & 0.016 & 121 & 0.9 & 18 & 3 & 2.25 & 1.5 & 1.12 & 0.9 & 0.75 & 0.6 & 0.45 \\
\hline
\end{tabular}

\begin{tabular}{|l|l|l|l|l|l|l|l|}
\hline & $\mathrm{i}$ & 1 & 2 & 3 & 4 & 5 & 6 \\
\hline$* * *$ & $\mathrm{t}_{\mathrm{w}}$ & 1.4 & 1.1 & 0.9 & 0.8 & 0.7 & 0.6 \\
\hline$* *$ & $\mathrm{~d} / \mathrm{t}_{\mathrm{w}}$ & 71 & 90 & 111 & 125 & 142 & 167 \\
\hline
\end{tabular}

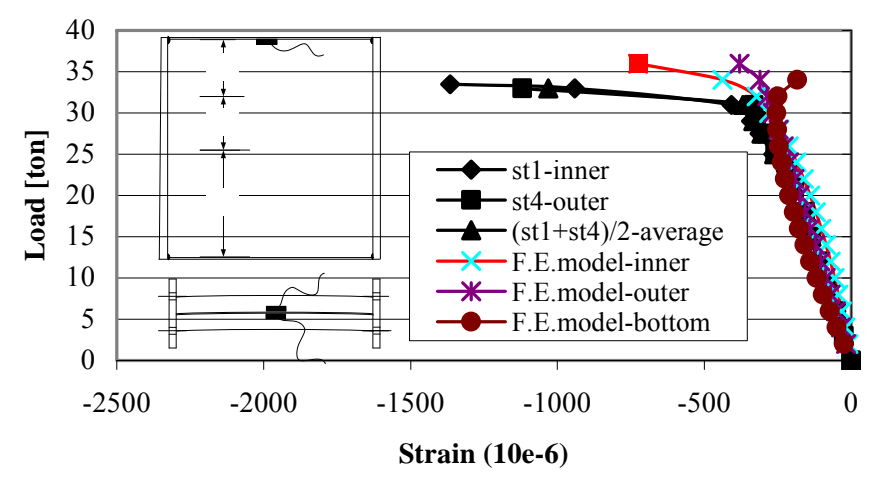

Fig. (3) comparison between experimental and F.E. model for strain in panel B3 


\section{PARAMETRiC STUdy Results}

\section{The applicability of the proposed equation}

Figure (4) presents the relationships between the applied stress at the top of the panel $\mathrm{N}_{\mathrm{o}}$ and the maximum out-of-plane displacement $w_{\max }$ for curved panels of group 1 .

Using the proposed equation (1) to find $\mathrm{d} / \mathrm{t}_{\mathrm{w}}$ limit for group 1 panels $(\mathrm{R}=4000 \mathrm{~cm}, \mathrm{~d}=100 \mathrm{~cm}$, $\alpha=1$ ) it give that $d / t_{w}$ should be less than 95 (for the stress $f \leq f_{y}=2.8 \mathrm{t} / \mathrm{cm}^{2}$ ), and that the out of plane displacements are limited to $0.83(\mathrm{~d}=100 \xi=120)$. The same result can be obtained from figure (4), since the maximum out-of-plane displacement $\left(w_{\max }\right)$ of panels Bt1-1-40-(1) and Bt21-40-(1) do not exceed the limit (for the stress $f \leq f_{y}=2.8 \mathrm{t} / \mathrm{cm}^{2}$ ) where the other panels do, which verify the applicability of the proposed equation (1).

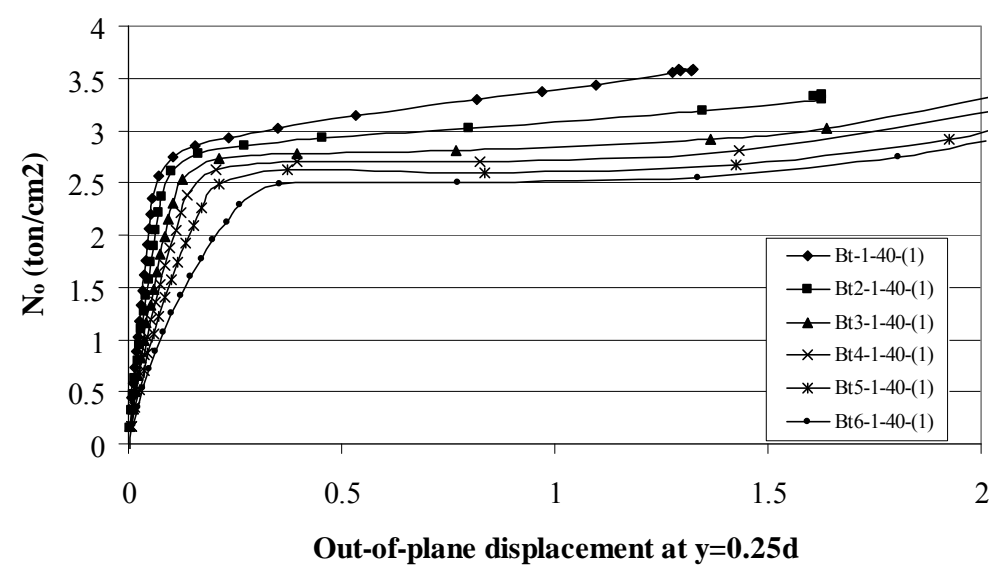

Fig. (4) Relationship between the max applied stress $N_{0}$ and max out-of-plane displacement $w_{\max }$

\section{Flange's slenderness effect with change of curvature}

The analytical procedure for the proposed equation deals with the curved thin-walled panels as a simply supported plate, neglecting any lateral displacement for the flange. The next extensive study is done for the curved panels having a web slenderness limitation with different flange slenderness and different curvatures (groups 2, 3, 4 and 5).

Figure (5) shows that for the four groups considered in the presented study, the effect of the curvature in calculating the suitable slenderness of flange to satisfy the proposed equation can be ignored. In other words, the effect of the flange slenderness on the web buckling is insignificant.

\section{Flange's slenderness effect with change of depth}

The next study considers the curved panels having a web slenderness limitation with different flange slenderness and different depth parameter (groups 3, 6 and 7).

Figure (6) indicates that the out-of-plane displacement depends not only on the slenderness of the web but also on the slenderness of the flange, whereas the slenderness of the flange must be limited to prevent the web buckling.

The effect of curvature in calculating the suitable slenderness of the flange is neglected to prevent web buckling as mentioned before. Euro Code 3 [8] presents the relation between the web and flange slenderness (as shown in equation (2)) to prevent the possibility of the 
compression flange to buckle in the plane of the web, before attainment of yield stress in the flange due to flexure,

$\frac{1}{0.55}\left(\frac{\mathrm{f}_{\mathrm{yf}}}{\mathrm{E}}\right) \frac{\mathrm{d}}{\mathrm{t}_{\mathrm{w}}}<\left(\frac{\mathrm{A}_{\mathrm{f}}}{\mathrm{A}_{\mathrm{w}}}\right)^{0.5}$

Where $\mathrm{f}_{\mathrm{yf}}$ is the flange yield stress

Table (3) indicates the validatation of equation (2) for curved thin-walled panel subjected to bending.

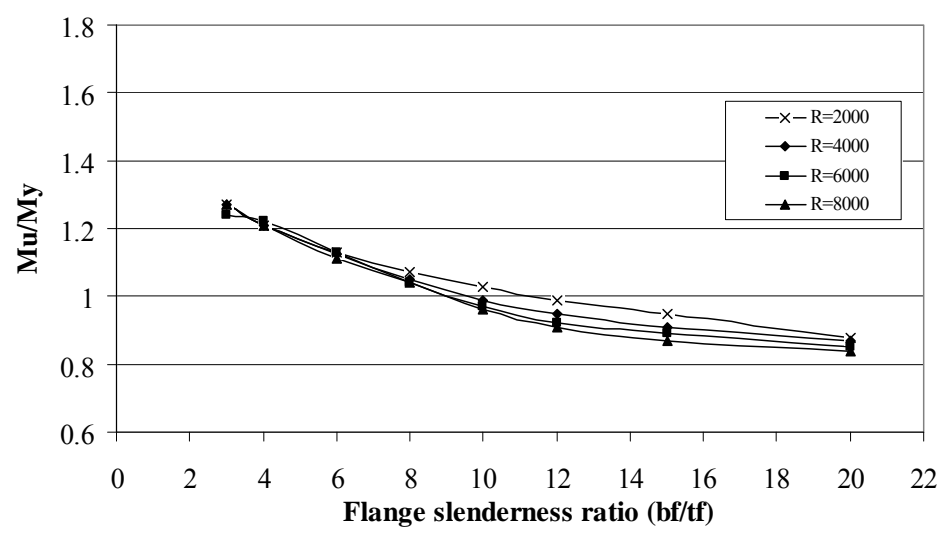

Fig. (5) Relationship between moment capacity and flange slenderness ratio with change of curvature

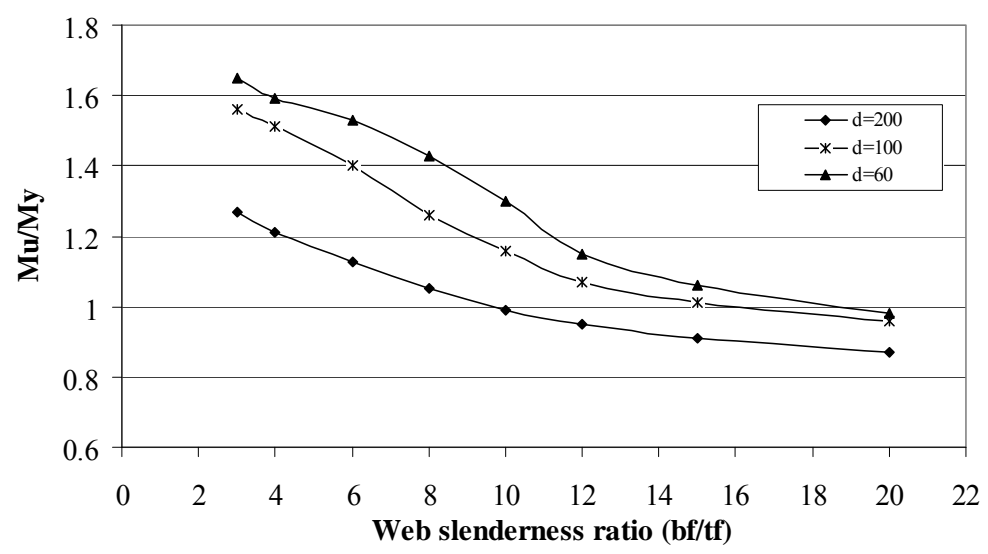

Fig. (6) Relationship between moment capacity and flange slenderness ratio with change of depth

\section{FLANGE'S SLENDERNESS EFFECT WITH CHANGE OF ASPECT RATIO}

The next study is for the curved panels having a web slenderness limitation with different flanges slenderness and different aspect ratios (groups 8, 9, 10 and 6). 
Figure (7) indicates that special consideration must be taken for the panel having $\alpha>1$, for $\alpha>1$ flange slenderness limitation given by equation (2) is not valid and the flange slenderness must be limited to the slenderness ratio of compact flange.

Table (3) flange slenderness limitation eq. (2)

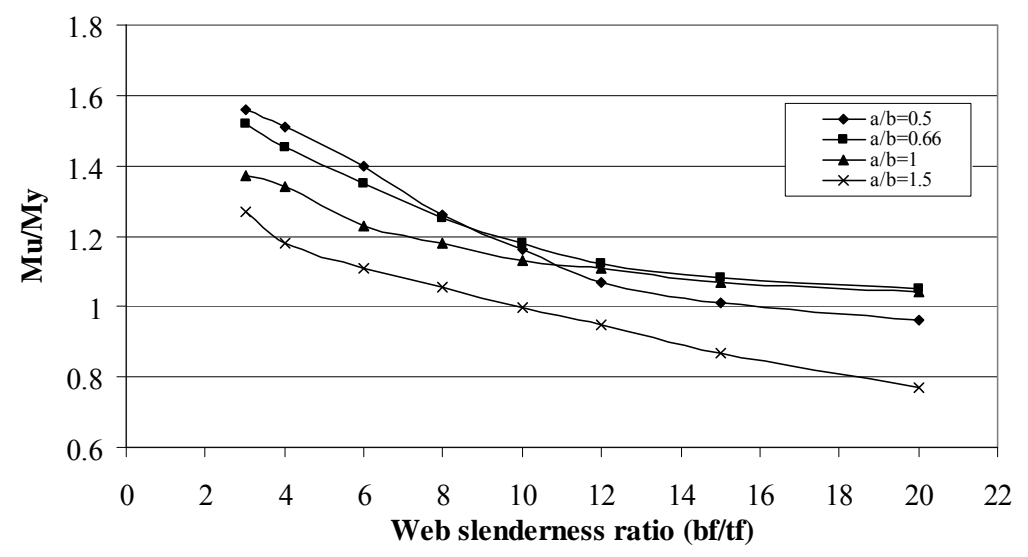

Fig. (7) Relationship between moment capacity and flange slenderness ratio with change of aspect ratio

\section{CONCLUSION}

\begin{tabular}{|c|c|c|c|c|c|c|c|c|}
\hline panel & $\mathrm{d}(\mathrm{cm})$ & $\mathrm{tw}(\mathrm{cm})$ & $\mathrm{bf}(\mathrm{cm})$ & $\mathrm{tf}(\mathrm{cm})$ & $\begin{array}{c}\text { LHS of } \\
\text { eq. }(2)\end{array}$ & $\begin{array}{c}\mathrm{d} / \mathrm{t}_{\mathrm{w}} \\
\mathrm{x} 412.5\end{array}$ & $\begin{array}{c}\text { Eq. } \\
\text { validation }\end{array}$ & $\begin{array}{c}w_{\max } \mathrm{F} . \mathrm{E} . \\
\text { B1-2-40-(0.5) }\end{array}$ \\
\hline B3-2-40-(0.5) & 200 & 1.6 & 24 & 4 & 0.547 & 0.303 & Valid & In limit \\
\hline B5-2-40-(0.5) & 200 & 1.6 & 24 & 2 & 0.387 & 0.303 & Valid & In limit \\
\hline B4-1-40-(0.5) & 100 & 0.7 & 18 & 1.125 & 0.621 & 0.346 & valid & In limit \\
\hline B7-0.6-40-(0.5) & 60 & 0.4 & 14 & 0.46 & 0.522 & 0.291 & Valid & In limit \\
\hline
\end{tabular}

An extensive parametric study has been conducted over 78 curved thin-walled panel (divided into 10 groups) using finite element model. The applicability of the theoretical analysis has been verified. The effect of the flange slenderness is studied with the change of curvature, depth and aspect ratio. The effect of the flange slenderness on the web buckling is not nearly affected by the change of curvature, which mean that the slenderness of the straight flange can be taken to the curved flange for the panel with the same dimension. The flange slenderness limitation of the straight panel can be used for calculating the flange slenderness limitation of curved thin-walled panel with aspect ratio less than 1. For curved thin-walled panel with aspect ratio more than 1 , the flange slenderness must be limited to the slenderness of compact flange.

\section{REFERENCES}

[1] Kang Y. J. and Yoo C. H., "Thin-walled curved beams. I: Formulation of Nonlinear equations", Journal of Engineering Mechanics, ASCE, Vol.120, No.10, October, 1994, 2072-2101. 
[2] Culver C. G., Dym, C. and Brogan D., " Bending behavior of cylindrical web panels ", Journal of the Structural Division, ASCE, Vol. 98, No. 10,1972,2201-2308.

[3] Nakai H. and Yoo C. H., "Analysis and design of curved steel bridges", McGraw-Hill, New York. 1988.

[4] Davidson JS, Balance CR, Yoo CH., "Analytical model of curved I-girder webs subjected to bending", Journal of Bridge Engineering, ASCE, Vol. 4, No.3, 1999a, 204-212.

[5] Davidson JS, Balance CR, Yoo CH., "Finite displacement behavior of curved I-girder webs subjected to bending", Journal of Bridge Engineering, ASCE, Vol. 4, No.3,1999b 213-220.

[6] Yossef N. M., Hassanen M., Dabaon M., El-Boghdadi M., and Elaghoury M., "Analytical Bending Behaviour of Curved Thin-Walled Panels", 2008 Structure Congress Conference, Vancouver, Canada, 24-26 April 2008.

[7] Dabaon M., El-Boghdadi M., Yossef N.M., Hassanen M. and Elaghoury M., "Analytical and experimental study of horizontally curved thin-walled panel subjected to bending moment", Third International Conference on Structural Engineering, Mechanics and Computation (SEMC 2007), Cape Town, South Africa, 10-12 September 2007.

[8] Eurocode 3 "Design of steel structure", Part 1.1 general rules and rules for buildings. ENV1993-1-1:1992. 